\title{
DESAFIOS À EDUCAÇÃO PARA A AUTORIA NA ESFERA ACADÊMICA
}

\author{
Mary Elizabeth Cerutti-Rizzatti \\ Universidade Federal de Santa Catarina \\ Florianópolis, Santa Catarina, BR \\ Adriana de Carvalho Kuerten Dellagnelo* \\ Universidade Federal de Santa Catarina \\ Florianópolis, Santa Catarina, BR
}

\begin{abstract}
Resumo
Este artigo tem como tema "a educação para a autoria na universidade"; organiza-se para responder à seguinte questão-problema: Que desafios se colocam à educação para a autoria na esfera acadêmica hoje? Para tanto, o texto se delineia a partir de uma filiação teórico-epistemológica de base histórico-cultural, contemplando uma abordagem compreensivista na geração e na análise dos dados, os quais derivam de um conjunto de estudos já consolidados ou em fase de consolidação no Grupo de Pesquisa "Cultura Escrita e Escolarização" da Universidade Federal de Santa Catarina. Como resposta à questão-problema, argumenta-se haver, dentre outros tantos, três grandes desafios de substantiva relevância na educação para a autoria: (i) apropriação de conhecimentos tensionada por fundamentos relativistas na esfera escolar; (ii) expectativas acadêmicas nas relações com posturas de condescendência; e (iii) atenção seletiva como contraface da ausculta. Defende-se que uma educação para a autoria nessa esfera implica a ampliação de repertório cultural dos sujeitos ao longo de seu percurso formativo na busca por consolidar uma condição de autonomia em relação à heteronomia nessa mesma esfera.
\end{abstract}

Palavras-chave: Autoria; Apropriação de Conhecimento; Ausculta; Autonomia; Heteronomia.

\section{CHALLENGES OF EDUCATION FOR AUTHORSHIP IN THE ACADEMIC SPHERE}

\begin{abstract}
The topic of this article is "Education for authorship in university"; it is organized to answer the following question: What challenges does the academic sphere face as regards education for authorship today? In order to answer that question, the text spouses a theoretical-epistemological affiliation of a historical-cultural basis, employing a comprehensive approach in the generation and analysis of data, which derive from a number of studies consolidated or in phase of consolidation in the Research Group "Writing Culture and Schooling" of Universidade Federal de Santa Catarina. In response to the research question, it is argued that there are, among many others, three major challenges of substantive relevance in education for authorship: (i) appropriation of knowledge tensioned by relativistic fundamentals in the school sphere; (ii) academic expectations with condescending attitudes; and (iii) selective attention as opposed to auscultation. It is argued that an education for authorship in the academic sphere involves the expansion of individuals' cultural repertoire throughout their education so as they consolidate a condition of autonomy in opposition to heteronomy.
\end{abstract}

Keywords: Authorship; Appropriation of Knowldege; Auscultation; Autonomy; Heteronomy.

\footnotetext{
Possui doutorado em Letras pela Universidade Federal do Rio Grande do Sul e pós-doutorado em Filosofia da Linguagem na Università degli Studi Aldo Moro, na Itália. É professora da Universidade Federal de Santa Catarina com experiência na área de Linguística e Letras. Tem interesse por estudos sobre ensino e aprendizagem de Língua Portuguesa, estudos acerca de relações entre cultura escrita, formação humana integral e processos de escolarização; interessa-se, ainda, por temas relacionados à formação de professores de Língua Portuguesa, alfabetismo e usos sociais da escrita. Seu endereço de email é ma.rizzatti@gmail.com

${ }^{* *}$ Possui mestrado e doutorado junto ao Programa de Pós-Graduação em Estudos Linguísticos e Literários da UFSC e pós-doutorado em Linguística Aplicada pela Penn State University. É professora associada do Departamento de Língua e Literatura Estrangeiras da UFSC, com experiência em ensino presencial e a distância. Seu interesse de pesquisa centra-se na área de formação de professores de línguas, da preparação às práticas ao desenvolvimento profissional do professor de línguas em contextos pré-serviço e em-serviço. Seu endereço de email é adrianak@cce.ufsc.br
} 


\section{Introdução}

A escrita na universidade constitui tema de relevância substantiva no Brasil, sobretudo, nas últimas décadas, a partir da ampliação das condições de acesso ao ensino superior para um grupo maior da população, incluindo segmentos sociais historicamente alijados da plena escolaridade. Nos últimos anos, ampliaram-se políticas públicas voltadas para a implementação dessas condições de acesso - em que pesem controvérsias acerca delas - quer por meio da educação a distância ${ }^{1}$, quer por meio de sistemas de $\operatorname{cotas}^{2}{ }^{2}$ quer pela progressiva ampliação da obrigatoriedade dos anos de permanência na escola, demandada tanto por legislações respectivas a esse campo ${ }^{3}$ quanto por exigências de um mercado crescentemente mais caracterizado pela automação e pela informatização (RONCAGLIA, 2010) e que, em razão disso, tende a favorecer a adoção de posturas educacionais produtivistas. ${ }^{4}$

$\mathrm{O}$ afluxo desse novo grupo de cidadãos à esfera acadêmica, grupo caracterizado, dentre outras especificidades, pelo não pertencimento às elites escolarizadas, trouxe para essa mesma esfera um desafio até há pouco tempo inédito: constituir-se por acadêmicos cujo repertório cultural distingue-se substancialmente daquele historicamente característico da esfera acadêmica. Essa disparidade nas vivências com a escrita dos novos estudantes em relação àquelas vivências tidas como "esperadas" no ensino superior parecem impactar de diferentes modos a constituição dessa mesma esfera acadêmica e tende a ser interpretada sobremaneira como "lacuna", "deficiência" ou (não)apropriação de determinados gêneros do discurso (BAKHTIN, 2003 [1952-53]), esses últimos tomados nesta discussão como instituindo relações interpessoais na universidade, gêneros cujo domínio se coloca como instrumental - no sentido vigotskiano do termo - na efetiva imersão dos acadêmicos na educação superior e em sua habilitação profissional.

Já em se tratando dos estudantes daqueles grupos que historicamente se caracterizam por plena escolaridade, ${ }^{5}$ o que tende a prevalecer nas elites socioeconômicas, o desafio que se impõe à esfera acadêmica parece ser de outra ordem, mas não menos inquietante: as novas gerações, nativas da era tecnológica e com amplo acesso aos bens de consumo que materializam tal época da atividade humana, como computadores e celulares de última geração, com navegação em redes de alta velocidade, vêm paulatinamente requerendo uma aceleração da atenção seletiva (com base em VYGOSTKI, ${ }^{6} 2012$ [1931]) que coloca em xeque a configuração histórica da universidade também no que respeita aos gêneros do discurso que lhe são fundamentais. Essa característica parece-nos também extensiva ao grupo que mencionamos anteriormente, mas possivelmente com constrições econômicas para acesso à diversidade desses bens e alcance de suas potencialidades de uso.

Assim, para estudantes neófitos no espaço acadêmico, o desafio tende a ser a lógica de erudição que se materializa, dentre outros modos, sob demandas de uso da norma culta da língua (com base em FARACO, 2008), tanto quanto a familiarização com artefatos de escrita vinculados à ideologia oficial (VOLÓSHINOV, 2009 [1929]; BAKHTIN [VOLOCHÍNOV], 2010 [1927]) e, o mais importante, com representações de mundo a eles correlatas. Já para os grupos sociais socioeconomicamente privilegiados que desfrutaram da esfera acadêmica na genealogia familiar e para as quais tais artefatos tendem a estar a sua disposição desde o berço, o desafio parece ser dispor-se a investir o tempo de atenção que a erudição acadêmica historicamente demanda e que parece incompatível com a velocidade dos potentes dispositivos eletrônicos com os quais operam em seu cotidiano e que confiscam sua atenção para estímulos concorrentes que se sucedem e se pospõem em alta velocidade de alternância. Seguramente essa é uma questão que diz respeito a todos os segmentos da população, mas recrudesce em relação proporcional com o potencial econômico dos sujeitos.

Assim considerando, este artigo ocupa-se desses desafios, delimitando-se ao tema "educação para a autoria na esfera acadêmica”, e buscando responder a esta questão de pesquisa: Que desafios se colocam à educação para a autoria na esfera acadêmica hoje? Responder a essa questão requereu de nós coerência com o tipo de pesquisa que temos feito, de base compreensivista (MINAYO, 2014 [1993]). Colocamo-nos diante de nosso objeto de estudo com o intuito de compreender as 
complexas relações que entendemos haver nele e, nessa condição, distinguindo-nos de abordagens ocupadas com cuidados positivistas de geração e análise de dados na/após a imersão em campo.

Sob essa base, lidamos com um conjunto de dados que vêm sendo gerados no âmbito do Grupo de Pesquisa "Cultura Escrita e Escolarização" - UFSC/SC, em estudos em fase de consolidação e também em estudos já consolidados, ${ }^{7}$ a partir de vivências dos pesquisadores com graduandos em diferentes cursos. Tais dados vêm compondo um conjunto de produções articuladas e vêm sendo retomados, em aspectos pontuais não discutidos nos estudos de origem, em aberturas para novas publicações, sob novos ângulos, como se dá no presente artigo. Assim, lidamos fundamentalmente com excertos de entrevistas ou rodas de conversa, com documentos e com vinhetas narrativas derivadas de nossos vários diários de campo correspondentes a tais estudos. A análise dos dados obedece à proposta de Cerutti-Rizzatti e Goulart (2016), que será precisada na segunda seção de conteúdo deste artigo.

\section{Educação para a autoria em textos nos gêneros do discurso da esfera acadêmica: fundamentos para a discussão.}

Compreendemos que a educação para a autoria na esfera acadêmica implica apropriação de conhecimento que se dá nas relações interpsíquicas (com base em VYGOTSKI, 2012 [1931]), o que transcende, por exemplo, o aprendizado notacional de como reportar o discurso de outrem (com base em BAKHTIN, 2011 [1929]), para requerer a consolidação paulatina do estado de intersubjetividade (com base em WERTSCH, 1985). Assim considerando, o ato (com base em BAKHTIN, 2010 [1920-24]) de escrever na universidade exige que o acadêmico se coloque em posição de ausculta ${ }^{8}$ (com base em PONZIO, 2010; 2013; 2014) em relação ao outro, especialmente em relação aos autores dos textos cujas leituras lhe são demandadas; e esse é um processo que exige tempo de imersão, como discutido em Cerutti-Rizzatti e Lesnhak (2015).

Compreender a educação para a autoria a partir dessas bases remete à intensificação das vivências dos acadêmicos com esses diferentes outros, em interações de toda ordem - para o foco desta discussão, mediadas pela escrita -, que criem possibilidades de alargamento de suas representações da realidade natural e social (com base em VOLOCHÍNOV, 2013 [1930]). Importa desafiá-los a um olhar exotópico em relação àquilo que lhes é familiar, tanto quanto convidá-los a imergir em especificidades da cultura escrita que caracterizam o grande tempo (com base em BAKHTIN, 2003 [1979]), na busca de colocá-las também sob escrutínio, tendo como fito o tensionamento entre cotidiano e história (com base em HELLER, 2014 [1970]).

Ancorando-nos fundamentalmente em uma base vigotskiana, vêm nos inquietando, sobretudo nos últimos anos, olhares no campo da educação em linguagem que colocam em xeque o compromisso da esfera escolar com a mencionada imersão na cultura escrita no que respeita à história, no sentido que Heller (2014 [1970]) dá ao conceito. Referimo-nos a concepções partidárias do relativismo cultural $^{9}$ que problematizam exatamente aquilo que entendemos estar na articulação do presente com o passado, em prospecção com o futuro. Tendências tais têm contribuído para a gaseificação da função escolar, ${ }^{10}$ historicamente incumbida de tensionar o cotidiano em que os sujeitos vivem com o que é do âmbito do genérico humano, no termos de Heller (2014 [1970]); e, sob um ponto vista vigotskiano, com o que é do âmbito da ontogênese.

Essa face que a esfera escolar vem assumindo, permeada fundamentalmente por compreensões teóricas fundadas no mencionado relativismo, a nosso juízo tem contribuído de modo decisivo para que, tanto os segmentos sociais neófitos na esfera acadêmica, como aqueles segmentos da população a ela afinados pela tradição de privilegiamento socioeconômico, cheguem à universidade marcados por um encapsulamento no cotidiano e não lhes sejam facultadas condições para a [cons] ciência do que é do plano do genérico humano. Entendemos, no entanto, que esses novos traços que se delineiam em muitos espaços educacionais em nível nacional não tendem a afetar tão efetivamente as elites socioeconômicas escolarizadas, para as quais a esfera escolar não constitui instituição de "impacto" definitivo, dada a imersão cultural mais ampla que condições 
monetárias favoráveis facultam a esses sujeitos. Assim considerando, vivências em viagens, acesso a bens culturais diversificados, imersão em espaços familiares marcados por artefatos de prestígio cultural compõem a esfera familiar e esferas afins no caso desses segmentos populacionais, ampliando seu repertório de vivências culturais, o que não parece ser a realidade dos estratos sociais alijados do privilegiamento econômico. Com relação a esse tema, mas focalizando o acesso à leitura, Britto (2015, p. 141) escreve: "[...] os mais excluídos da leitura são também os mais excluídos da sociedade, os que não têm bons empregos (muitas vezes nenhum), não têm moradia, atenção à saúde, direito ao lazer." E também: "A escrita e a leitura sempre foram, e continuam sendo, instrumentos de poder e, nesse sentido, sempre estiveram, e continuam estando, articuladas aos processos sociais de produção do conhecimento e de apropriação dos bens econômicos." (p. 140)

Compreendemos, pois, que, em se tratando dos universitários "naturalmente" imersos em uma ambientação de acesso aos bens culturais de prestígio, a impermeabilidade à tradição da esfera acadêmica tende a derivar da "imobilidade" dessa esfera se comparada à velocidade da era tecnológica atual das mídias de todo tipo com as quais operam - não raro de modo compulsivo - em seu cotidiano. Já para os demais, tal impermeabilidade parece associar-se mais efetivamente à prática do mistério, nos termos de Lillis (2001): o que está sendo requerido no campo da autoria parece ser claro para todos aqueles que já estão imersos na escrita de prestígio, mas não para os sujeitos cujas vivências com essa mesma escrita só poderiam ter tido lugar na esfera escolar na Educação Básica e, em se gaseificando essas vivências em nome do relativismo cultural, veemse em meio ao mistério.

Com isso não defendemos a manutenção de requisitos de autoria na esfera acadêmica isomórficos às vivências dos segmentos sociais de privilegiamento econômico, contra o que já se coloca toda uma tradição dos "estudos culturais" e do "pós-estruturalismo" - ainda que nos distingamos das bases em que essa correntes se fundamentam -, entre outros enfoques. Entendemos, porém, que um esvaziamento das vivências com a cultura escrita vinculadas ao genérico humano, em nome da denegação de posturas de exclusão correlatas a uma tradição escolar culturalmente elitista e marcada por relações assimétricas de poder, parece estar, em boa medida, contribuindo exatamente para o decantado quadro de exclusão. Dizendo de outro modo: ao se apagar, na escola, o que é do âmbito da ontogênese, tende-se a fazê-lo de fato apenas para os segmentos alijados dos bens culturais dominantes, porque aqueles segmentos com acesso a tais bens fora da escola não serão afetados pela herança de relativismo cultural que ganha corpo dia a dia na esfera escolar, isso porque suas vivências extraescolares tendem a lhes assegurar condições para que tomem ciência daquilo que respeita ao genérico humano.

Assim considerando e retomando o foco desta discussão, entendemos que a educação para a autoria na esfera acadêmica não pode se limitar a atividades de bases notacional, operacional, estrutural ou afins, nem a bases discursivas apenas. Não nos parece que objetificando os gêneros do discurso (com base em GERALDI, 2010), conferindo-lhes uma estabilidade que não é compatível com a lógica do próprio conceito, seja possível educar os sujeitos para a autoria, a exemplo de encaminhamentos vinculados a "como fazer uma resenha", "como escrever um artigo acadêmico" e afins, ao que se acresce toda uma literatura de apelo de mercado que alimenta esses propósitos, inócuos na origem.

Disciplinas acadêmicas do campo da Produção Textual tendem a se organizar com enfoques tais há algum tempo, e não nos parece que, a partir deles, venha se consolidando a educação para a autoria. Nossas experiências em docência nelas, mesmo que sob "nobres" propósitos, têm sinalizado para essa inoperância. Com elas, temos aprendido que acadêmicos tendem a manter-se sob efeitos de orientações dessa ordem ao longo das disciplinas que as tomam como objeto de ensino, desvencilhando-se dessas orientações tão logo não estejam mais dependentes dos "créditos" correspondentes a essas mesmas disciplinas, o que leva docentes, ao final da graduação, a interpelarem seus alunos na busca de saber por que/se "não cursaram disciplinas em que lhes tenham ensinado questões notacionais, normativistas e afins". Se o fizeram, como "não sabem escrever"? Certamente o pragmatismo não é resposta para a com- 
plexidade desse quadro, no qual as vivências culturais constituem componente relevante.

Em nossa compreensão, resultados como esses vêm se replicando na esfera acadêmica com estudantes em sobejas dificuldades para se assumirem como autores de textos nos gêneros do discurso dessa esfera, o que transcende questões pontuais para colocar-se no plano das representações acerca da realidade natural e social (com base em VOLOCHÍNOV, 2013 [1930]), sem cujo alargamento a autoria parece-nos um vir-a-ser, mesmo que o estudante possa arrolar com excelência todas as características que distinguem um resumo indicativo de um resumo informativo, à guisa de exemplo prosaico.

Parece-nos que os movimentos da chamada "virada linguística", como resposta ao questionamento a enfoques epistêmicos e ontológicos, têm contribuído para que se repute à linguagem a centralidade do olhar dos sujeitos; afinal, a grande questão seriam os "jogos de linguagem", como adverte Lyotard (2013 [1979]). Logo, escrutinando-se os "modos de dizer", escrutinar-se-ia o "dizer" em si mesmo? Uma base vigotskiana nos leva a caminho distinto: advogar em favor de fundamentos epistêmicos e ontogenéticos, concebendo a língua não como o centro do processo, mas como instrumento psicológico de mediação simbólica, que faculta a sociointeração e a organização do pensamento (com base em VIGOTSKI, 2000 [1968]).

Uma orientação com esses contornos na discussão da autoria nos faz ter presente que, para que o sujeito se enuncie na esfera acadêmica, na materialidade textual em um gênero do discurso, importa que tenha vivenciado amplos processos de interlocução mediados pela linguagem - neste caso, especialmente a modalidade escrita. Importa, ainda, que, no âmbito desses processos tenha se consolidado, via estado de intersubjetividade (WERTSCH, 1985), um percurso de apropriação de conhecimento que lhe permita assumir-se como autor no tratamento de suas representações de mundo acerca de um determinado objeto cultural tematizado, sempre ciente de fazê-lo não sob uma perspectiva subjetivista adâmica - ele próprio como origem do percurso em questão -, mas inserto na cadeia ideológica (com base em VOLÓSHINOV, 2009 [1929]; VOLOCHÍNOV, 2013 [1930]).
Desse modo, para que um acadêmico produza textos em gêneros do discurso com tradição nas interlocuções na universidade, transcendendo a condição de plágio (com base em LEA; STREET, 1998) e dirimindo a prática do mistério (LILLIS, 2001), requer-se mais do que relativizar as expectativas acadêmicas em nome de uma lógica de foco na cultura, tomada distintamente de suas relações com a história - o local sobrepondo-se ao universal -, tanto quanto mais do que dominar formas de lidar com o discurso reportado no simpósio universal (com base em BAKHTIN, 2011 [1929]). Requer-se ampliação das representações de mundo para colocarse diante das várias vozes reportadas, tendo parâmetros para uma postura crítica diante delas e repertório para responder a elas assinando o ato, no sentido que Bakhtin ${ }^{11}$ (2010 [1920-24]) dá ao conceito. Esses parâmetros, em nossa compreensão, implicam apropriação de conhecimento, que entendemos se dar do âmbito do que é interpsíquico para o que é intrapsíquico (VIGOTSKI, 2000 [1968]).

Um processo de apropriação tal, por sua vez, implica atenção ao genérico humano (HELLER, 2014 [1970]), ao que está no plano da ontogênese (VYGOTSKI, 2012 [1931]), ao que se coloca no grande tempo (com base em BAKHTIN, 2003 [1979]). Não entendemos possível uma formação para a autoria na esfera acadêmica destituída de um processo de apropriação de conhecimento, que inclua tanto o campo conceitual do objeto cultural em foco na textualização como o campo conceitual das questões ligadas à textualidade em si mesma, aí incluídos conceitos como argumentação, persuasão, convencimento, contradição, síntese e afins. E, também sem dúvida, do campo conceitual respectivo a questões de poder, coerção, interdição e congêneres.

Problematizamos, assim, uma educação para a autoria colocada nos limites discursivos, procedimentais e/ou processuais dos "modos de dizer e de fazer"; concebemos a conformação discursiva, os procedimentos e os processos como importantes componentes desse percurso educacional, mas seguramente não como sinônimos dele. Para nós, a centralidade da educação para a autoria na esfera acadêmica está intrinsecamente relacionada à apropriação do conhecimento; e, sob a perspectiva vigotskiana, entendemos que a educação 
para a leitura é questão nodal a ser discutida nesse campo. Para tanto, distinguimo-nos de abordagens que tomam leitura e ler com enfoques cognitivistas intransitivos, para assumirmos um olhar que se dispõe a lidar com o ato de ler textos em gêneros do discurso e, em assim sendo, implica ler o que foi escrito por outrem para uma finalidade interacional específica, em uma inserção histórico-cultural também específica e com o enfoque em um objeto cultural determinado. E mais: demandando uma resposta (com base em VOLÓSHINOV, 2009 [1929]). Britto (2015, p. 66) entende que, dada essa transitividade, "[...] ao indagar sobre a leitura [...] há que se indagar também sobre os objetos sobre os quais ela incide, os modos como se realiza, as relações que se estabelecem em função dela, etc." Logo, ler é ler a escrita do outro sobre um objeto cultural a partir de um ponto de vista historicizado, e isso requer tempo de atenção de quem lê.

Aqui se coloca um importante desafio na educação para a autoria e ao qual já fizemos alusão no início deste artigo: a disposição dos sujeitos para o endereçamento da atenção seletiva (com base em VYGOTSKI, 2012 [1931]) ao que foi escrito por outrem. Isso porque um processo de apropriação conceitual na relação com esse outro, autor, exige que a ausculta se dê, o que Ponzio (2013; 2014) entende como o abrir-se para o outro, o dar tempo ao outro para que se enuncie; o calar e não o silenciar. Sobre a diferença entre esses dois últimos posicionamentos, Ponzio, Calefato e Petrilli (2007) concebem que o calar suscita calar fundo, ocorrendo quando endereçamos a essa palavra do outro a nossa atenção, não na busca de que ela convirja com a nossa palavra, mas na abertura para que ela se enuncie e que a ela respondamos. Já o silenciar implica não haver razões para romper o silêncio porque a palavra outra nos é indiferente. Escrevem os autores italianos: "Do calar do qual a enunciação parte como livre escolha, ao calar que ela requer, a que se dirige, a que se entrega e que a acolhe na escuta: esse é o movimento da enunciação" (p. 31).

Concebemos que apenas uma posição de ausculta por ocasião do ato de ler pode ser caminho para o estado de intersubjetividade com o outro - o autor - do que depende facultar-se aos acadêmicos apropriação de conhecimento na relação com esse outro, mediada pela escrita e pela interlocução mais experiente do professor universitário, e isso sempre sob o escrutínio de um olhar crítico; logo, não se trata de um olhar de assimilação, mas sempre de um olhar de refração (com base em VOLÓSHINOV, 2009 [1929]). E essa posição requer dar tempo ao outro, dar tempo para que ele se enuncie, como assinala o filósofo italiano; e possivelmente esse seja um dos maiores desafios da educação para a autoria na esfera acadêmica hoje.

Vivemos em uma época em que a atenção seletiva dos sujeitos tende a ater-se não mais de dez segundos em um estímulo específico para, em seguida endereçarse a outro, que urge por meio dos diversos sons de alerta dos dispositivos eletrônicos crescentemente mais entranhados no cotidiano contemporâneo (com base em RONCAGLIA, 2010). Nesse cenário, dar tempo para que o outro se enuncie, em se tratando da leitura, exige tempo para imersão no texto escrito, tempo para levantar os olhos do texto e pensar sobre ele (PONZIO, 2011). Essa discussão sobre "dar tempo a" vincula-se ao "parar para", que nos leva a Larrosa (2002, p. 24) ${ }^{12}$ na defesa da necessidade de "[...] parar para pensar, parar para olhar, parar para escutar, pensar mais devagar, olhar mais devagar, e escutar mais devagar; [...] abrir os olhos e os ouvidos, falar sobre o que nos acontece, aprender a lentidão, escutar aos outros, cultivar a arte do encontro, calar muito, ter paciência e dar-se tempo e espaço."

$\mathrm{Na}$ esteira dessa compreensão, buscamos problematizar o apagamento que entendemos haver em muitos espaços acadêmicos acerca das dimensões epistêmica e ontogenética das discussões sobre autoria; assumi-las nos leva a esta reflexão sobre apropriação de conhecimento. É possível ser autor sem ela? Compreendemos, entretanto, que não é possível projetar todas as lentes nos "modos de dizer" e nos "modos de fazer", sob pena de se delegar à língua o que entendemos ser delegável à intersubjetividade, e isso implica nos colocarmos contra a compreensão de que "tudo são jogos de linguagem".

Assim considerando, assumimos, neste aporte teórico, um olhar que compreende a educação para a autoria como necessariamente requerendo a educação 
para a ausculta do outro, a educação para o tempo de levantar os olhos do texto e pensar, a educação para apropriação dos objetos culturais implicados em uma formação omnilateral, compreendendo as relações dialéticas entre presente, passado e futuro como capitais nesse processo e, portanto, o necessário tensionamento entre o que é do âmbito da subjetividade e o que é do âmbito do genérico humano (HELLER, 2014 [1970]).

Uma última questão nos parece importante discutir neste registro de fundamentos teóricos, retomando o cuidado com os segmentos da população para os quais a formação escolar é [ou precisaria ser, mas não o faz] definitiva na ampliação do repertório cultural. A pujança das correntes vinculadas aos chamados "estudos culturais" vem mostrando a necessidade de atenção ao pertencimento dos sujeitos no que diz respeito a sua inserção cultural e, nesse âmbito, coloca-se no campo da escrita acadêmica a necessidade de a universidade abrirse para saberes outros que não aqueles dominantes. Ainda que não nos inscrevamos nesse corpo de estudos, convergimos na defesa de que a esfera acadêmica precisa abrir-se para aquilo que não compõe sua tradição. Isso, no entanto, não significa insularização no vernacular, como escreve Freire (2014 [1992], p. 98, grifos do autor), tão evocado por pesquisadores desse campo: "Jamais disse, como às vezes sugerem ou dizem que eu disse, que deveríamos girar embevecidos em torno do saber dos educandos, como a mariposa em volta da luz. Partir do "saber de experiência feito" para superálo não é ficar nele." Em uma perspectiva vigotskiana - distinta, portanto, também de Paulo Freire, mas atenta a ele -, entendemos tratar-se do movimento dialético entre conceitos espontâneos e conceitos científicos (VIGOTSKI, 2001 [1934]), o que não implica negação ou superação de nenhum deles, mas articulação dialética, em um tensionamento em que o sujeito escrutine o que lhe é familiar na apropriação crítica do que ainda lhe é estranho.

Desse modo, reiterando nossa filiação históricocultural e em uma tentativa de síntese das âncoras a partir das quais nos lançamos na próxima seção, compreendemos que a educação para a autoria na esfera acadêmica implica: (i) ressignificação do modo como a esfera escolar vem lidando com a apropriação dos objetos culturais que se colocam no grande tempo, na história, considerada a gaseificação que parece se dar em muitos espaços escolares em nome do relativismo cultural; (ii) problematização de eventual aplanamento das expectativas da universidade em relação aos neófitos nessa esfera - aplanar as exigências não nos parece uma forma de facultar a efetiva imersão daqueles para os quais lidar com elas é um desafio totalmente novo; (iii) persistência na compreensão de que educar para a autoria é educar para a ausculta, o que coloca em xeque a eventual rendição da esfera acadêmica à velocidade das tecnologias atuais. Compreendemos, assim, que a educação para a autoria requer a educação para o desenvolvimento psíquico a partir da intersubjetividade, o que só pode acontecer no âmbito da cultura - compreendida como produto da atividade humana historicizada na/sobre a realidade natural e social - e da história - compreendida como a articulação do presente com o passado na prospecção do futuro.

\section{Em busca de compreender especificidades da autoria na esfera acadêmica: nossos exercícios de olhar}

Tendo marcado nossa filiação teórica, apresentamos, nesta seção, dados gerados no âmbito do mencionado Grupo de Pesquisa "Cultura Escrita e Escolarização", os quais indiciam para as questões que vimos pontuando ao longo deste artigo. No processo de análise desses dados, vamos nos valer de ressignificação de proposta de Cerutti-Rizzatti e Goulart (2016) Figura 1 a seguir -, desenvolvida com base em CeruttiRizzatti, Mossmann e Irigoite (2013).

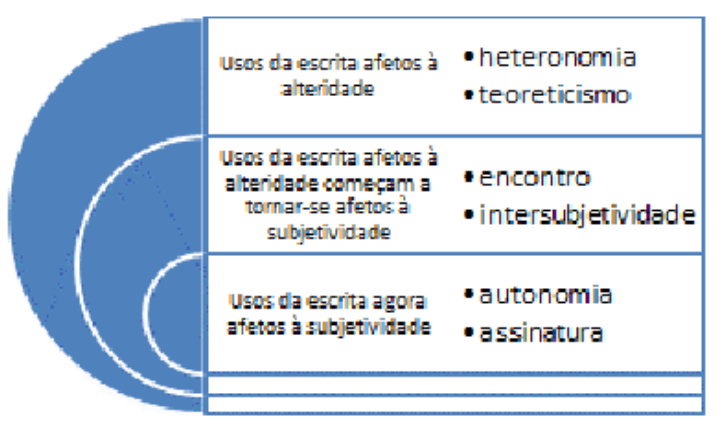

Figura 1 - O eu e o outro no processo de apropriação conceitual Ressignificação a partir de Cerutti-Rizzatti e Goulart (2016) 
Nessa Figura, temos no primeiro quadro uma condição de heteronomia - conceito tomado a partir do ideário vigotskiano -, o que nos leva ao teoreticismo de que trata Bakhtin (2010 [1920-24]). Em se tratando da educação para a autoria, nessa condição não se dá ainda a apropriação conceitual de que vimos tratando aqui, o que significa que o acadêmico precisa colocar-se como autor, mas ainda se vê em uma posição de heteronomia em relação ao professor, não tendo desenvolvido a autonomia para lidar sozinho com as demandas de autoria que lhe são colocadas. No segundo quadro, a partir das relações com o professor - desde que se dê o encontro base para a intersubjetividade ${ }^{13}$ (com base em CERUTTI-RIZZATTI; DELLAGNELO, 2016) -, desencadeiase um processo de apropriação conceitual, e o acadêmico começa a operar com aquilo que está em questão no projeto de autoria dele requerido de modo mais próximo como o faz o professor. No último quadro, enfim, coloca-se a condição de autonomia, tendo havido a apropriação do conhecimento; é, pois, possível, ao sujeito assinar o ato (com base em BAKHTIN, 2010 [1920-24]), assumindo-se como autor. Logo, não há mais teoreticismo - verdade dissociada do ato. Esse raciocínio, estreitamente articulado com as bases teóricas anteriormente registradas, pautará a análise dos dados a seguir.

Lidaremos, ao longo desta seção, com situações específicas em que esse percurso da heteronomia para a autonomia parece constituir desafio ainda a ser alcançado, estando nele implicados três componentes específicos já mencionados anteriormente: (i) rarefação da apropriação de conhecimentos no âmbito da esfera escolar; (ii) aplanamento das expectativas da universidade em relação às possibilidades de desenvolvimento dos acadêmicos; e (iii) aceleração da atenção seletiva como obstáculo na educação para ausculta. No movimento de análise, apresentaremos excertos de entrevistas, documentos e notas de campo dos mencionados estudos do Grupo de Pesquisa "Cultura Escrita e Escolarização". Para tanto, identificaremos cada dado a partir da seguinte codificação: GCEE - menção ao Grupo; Acadêmico do Curso X - menção ao participante de pesquisa; ano em que o estudo original foi realizado.

No que concerne às rarefações que entendemos estar havendo na esfera escolar quanto à apropriação de conhecimento, em se tratando daquilo que se coloca na história (HELLER, 2014 [1970]), na ontogênse (VYGOTSKI, 2012 [1931]), no grande tempo (com base em BAKHTIN, 2003 [1979]), compreendemos que essa apropriação cultural é importante fundamento para que os estudantes, sobretudo no início de seu processo de imersão na esfera acadêmica, possam transcender riscos de encapsulamento no cotidiano (com base em HELLER, 2014 [1970]) e estejam mais efetivamente educados para lidar com o que se coloca para além desse mesmo cotidiano. Em (1), (2) e (3) a seguir, registramos manifestações desses esvaziamentos no processo de formação básica, os quais tendem a cristalizar a condição de heteronomia, dificultando o movimento para a autonomia.

(1) Olha, ${ }^{14}$ eu acho que a gente não aprendeu quase nada, vamos dizer, a gente aprendeu bem pouco do que poderia ter aprendido, né, e::: Eu fiquei doze anos na [nomeia a escola] e quando entrei na faculdade::: nem sei::: parecia que eu não sabia NADA (+++), o professor de Literatura fala/ falava de coisa lá da História...NOSSA, parecia outro plane::ta... então era para fazer a resenha e comentar a obra considera::ndo a História... Cara, eu nem sabia do que ele estava falando (GCEE Acadêmico de fase I de Letras, dados de 2013).

(2) Eu não sei não (+++) acho que perdemos muito tempo na [nomeia a escola] Se eu soubesse que... depois ia ser diFÍCIL assim, tinha zoado menos. Na semana passada, tive a maior dificuldade para fazer o texto que o [menciona nome do professor] pediu (+) eu nunca entendi direito o que que é metáfora, como que podia escrever o que ele queria? Então não adiantou ele dar o manual com todos os passos para a gente escrever o texto... Eu tive que $i$ saber o que que era mesmo metáfora e não consegui, fiz uma porcaria de texto (GCEE - Acadêmico em fase I do Curso de Letras - dados de 2012).

(3) Eu vou te contar um vexamão que eu dei (+++) hoje eu posso te contar, mas passei um tempão bem mal por isso, foi BEM difícil... O professor [no início do Curso de Direito] começou a falar do príncipe [obra de Maquiavel] e eu entendi que era o pequeno príncipe [obra de Saint Exupery], tinha ouvido falar, mas não sabia o que era...Baixei o livro da internet, li tudo, mas achei SUPERchato... Quando cheguei na aula era outro livro e eu estava com o download do Pequeno Príncipe aberto 
no meu computador (+++) meu grupo todo viu, e claro que eu não consegui escrever o texto que ele queria. Fiquei até o fim do semestre pagando mico. (...) Na minha escola a gente nunca leu nada, nem ia pra biblioteca que estava sempre fechada. (GCEE - Acadêmico de fase II de Direito, dados de 2013)

Entendemos que as vivências na esfera escolar constituem a base para as vivências na esfera acadêmica e isso não pode ser desconsiderado por uma postura de relativismo cultural que se coloca na defesa dos sujeitos quando, na verdade, não raro termina por contribuir para fragilizar ainda mais aqueles segmentos que não têm na esfera familiar experiências para além do cotidiano imediato. Nesses casos e em outro tantos com que temos convivido, não nos parece estarem em questão apenas, pontualmente, conhecimentos da História humana - como requerido em (1) -, ou domínio conceitual da metáfora - como requerido em (2) -, ou ainda vivências com a literatura do grande tempo - como requerido em (3). Está em questão um percurso de formação que se esvazia do tratamento de questões relacionadas à ontogênese humana, em posturas educacionais que, em nome de problematizar enfoques de dominação e de poder, muitas vezes terminam por contribuir para esvaziar a esfera escolar de seu papel: tensionar o cotidiano e a história, problematizando ambos, tanto quanto remetendo à relação dialética existente entre eles.

A esfera do conhecimento especulativo é onde se verifica a presença contínua e sistemática do conhecimento organizado [...]. Ela supõe formas de organização e exposição distintas do falar e do pensar cotidiano. Exige a explicitação, referenciação e descontextualização do pensamento, o que, por sua vez, faz da metacognição procedimento intelectual fundamental para sua realização. (BRITTO, 2015, p. 69).

Entendemos que a autoria na esfera acadêmica implica esse processo, porque exige que o sujeito efetivamente organize suas formas de conceber a realidade natural e social e, para isso, tem de haver apropriação de conhecimento. Situações como as registradas de (1) a (3) implicam a permanência do acadêmico na condição de heteronomia, porque lhe está sendo requerido algo tido como "dado" - eis a prática do mistério (LILLIS, 2001) -, logo aborta-se o encontro (PONZIO, 2013; 2014), a intersubjetividade (WERTSCH, 1985), condição para a autonomia (com base em VYGOTSKI, 2012 [1931]; VIGOTSKI, 2000 [1968]), e, ao fazê-lo, não se educa para a autoria.

Reiteramos nossa ciência de que advogar em favor da apropriação de conhecimento como questão fundante da educação para a autoria é dissociarmo-nos de compreensões para as quais o que é do âmbito do racional, do ontológico e do conceitual está sob forte processo de denegação. Ratificamos, nessa ciência, a compreensão de que uma denegação dessa ordem, na Educação Básica, tende a fragilizar ainda mais as classes neófitas na esfera acadêmica - caso dos três graduandos que se enunciam de (1) a (3) e, caso, também, dos três graduandos que se enunciam de (4) a (6) a seguir, agora sob o segundo enfoque deste artigo, o aplanamento da esfera acadêmica.

(4) Vêm alunos assim, vamos dizer, com nível socioeconômico precário, né, e::: isso influencia também, e não é para ter comiseração "ah, coitadinho". NÃO, tem que ser exigido mesmo nível, né, mas acho (+) que tem que se dar mais apoio também [na escrita na esfera acadêmica]. (GCEE - Acadêmico do Curso de Letras, dados gerados em 2013).

(5) Eu vejo que tem uma diferença BEM GRANDE entre [menciona turnos em que o curso acontece]. Tive que fazer uma disciplina duas vezes $(+++)$ Olha, era a [nomeia a disciplina] e era [nomeia a professora] que dava aula nas duas vezes... Era TUDO o mesmo, mas de [nomeia o turno] ela aprofundava para caramba, exigia um MONte de escrita / e de [nomeia o outro turno] era tudo bem METAde (+) acho que porque estava todo mundo cansado do trabalho e ela ficava com pena de pegar pesado, né? A [nomeia uma aluna] sempre dormia na aula. Ali a gente escreveu quase nada... Acho que por isso que da segunda vez eu passei né? [risos] (GCEE - Acadêmico do Curso de Letras, dados gerados em 2013)

(6) Tem uma coisa que acho bem RUIM... [nomeia o professor] fica todo o tempo fazendo crítica para tudo e para todos...fala de preconceito, de 
coisa de poder, de política, de tudo (+++) Tá, mas a gente não discute o que tinha que ler (...) $o$ [nomeia novamente o professor] nem pede o que era para ler, mas lá com os alunos da pesquisa eles discutem tudo... Parece que para quem trabalha o dia todo é só discurso/ e para quem não trabalha e só estuda, aí tem leitura pesada, artigo e TUDO MAIS... (GCEE - Acadêmico de Letras, dados gerados em 2015).

Em que pese a complexidade do conteúdo desses excertos e o exíguo espaço para esta discussão, entendemos que aplanar as abordagens na educação para a autoria possivelmente seja um desafio que se coloque, mais uma vez, para as classes mais fragilizadas economicamente e, não por coincidência, também mais frágeis no que concerne ao entorno familiar escolarizado. Não raro, nas relações entre licenciatura e bacharelado, essas diferenças se exacerbam, o que novamente tende a remeter à historicidade dos estudantes que ingressam nesses cursos, considerados os indicadores de concorrência por uma vaga e, por implicação, os investimentos familiares - de economia e de valoração na formação dos sujeitos para o enfrentamento dessa mesma concorrência.

Assim considerando, para enunciar-se na esferaacadêmica, assumindo-se como autor, parece-nos requisito fundamental o aprofundamento conceitual, a diversificação das leituras, a multiplicação dos espaços para discussões coletivas, sempre na relação mediada com o professor. Nenhum tipo de "condescendência" nos parece justo, porque não se trata de condescender, mas de criar condições para que os sujeitos ampliem seu repertório cultural, sempre no tensionamento entre o já conhecido e o novo (com base em VIGOTSKI, 2001 [1934]) e nunca concebendo o não conhecido como "lacuna" ou "deficiência". Não raro a "defesa" dos grupos fragilizados termina por rarefazer, para eles, as situações em que poderiam apropriar-se do novo, desfazendo a prática do mistério (LILLIS, 2001). Nesses casos, em nossa compreensão, o esforço tende a se dar não para "desfazer" o mistério - aí o equívoco -, mas para descartar as propostas que instauram o mistério: abrimos mão de requerer a autoria dos acadêmicos naquelas situações que se mostram intrincadas para eles, ao invés de investirmos na sua educação para a autoria nessas mesmas situações, possivelmente porque essa segunda opção seja altamente custosa para nós em planejamento, dedicação de tempo, atenção às vivências dos sujeitos e, sobretudo para as finalidades deste artigo, criação de espaços fecundos para ampliação de seu repertório cultural. Dessa ampliação emerge a autonomia; abrir mão dela, implica condenar os sujeitos a uma condição ad infinitum de heteronomia.

Finalmente, com relação ao terceiro desdobramento em foco neste artigo, ocupamo-nos de obstáculos para a formação à ausculta, que entendemos profundamente relacionados ao dispêndio de tempo que estamos dispostos a investir nas relações com o outro. Tal como mencionamos anteriormente com Larrosa (2002), tempo para parar para pensar, o que nos leva à vinheta narrativa registrada em (7) a seguir.

(7) Inquieta-nos o modo como a maior parte dos graduandos desta fase lidam com os textos cuja leitura propomos. Muitos deles - cerca de seis em uma turma de dezoito - leem os textos em aparelhos celulares que cabem na palma da mão. São textos de teor filosófico, com muitas páginas, e eles se mantêm na leitura nas telas muito pequenas. Outros os leem em tablets ou na tela dos computadores portáteis; poucos os imprimem. O que tem nos chamado atenção é que, a despeito das especificidades de cada uma dessas opções - os textos são disponibilizados em plataforma on-line - o modo como quase todos selecionam a atenção é fracionado: os olhos alternam-se do texto para outros links, durante todo o tempo. Poucos dentre eles usam ferramentas de destaque de trechos ou aposição de comentários. Leem, mas tendem a ler de modo disperso, com idas e vindas do texto para outros focos de atenção, que reputamos envolver sobretudo redes sociais. Quando, ao final, thes requeremos que se enunciem por escrito acerca do que leram, a maior parte deles fazem-no com uma superficialidade e uma velocidade que nos contrariam profundamente. (GCEE - Vinheta narrativa 567 - docente do GCEE em disciplina do Curso de Letras; dados gerados em 2014).

A situação materializada em (7) remete a uma questão que vem nos inquietando em estudos diversos e que temos interpretado como uma aceleração da atenção seletiva (com base e VYGOTSKI, 2012 [1931]) nos 
espaços de ensino e aprendizagem, quer seja na Educação Básica, quer seja na Educação Superior e que, para as finalidades deste artigo, repercute na educação para a autoria porque está intrinsecamente relacionada com a constituição do sujeito leitor. Vimos presenciando uma crescente dificuldade dos acadêmicos para manter o foco de atenção em um mesmo estímulo por um período mínimo de tempo demandado para a interação com o outro por meio dele, o que se projeta fortemente em se tratando da leitura. Estímulos concorrentes superpõem-se, como se "em caráter de urgência", o que é amplamente favorecido pelos dispositivos eletrônicos e seus muitos sinais sonoros que deixam os sujeitos em constante estado de alerta; aparelhos nos quais tais sujeitos podem ter acesso simultâneo a vários estímulos, alternando o endereçamento da atenção a cada um deles, o que implica aceleração da manutenção em cada um dos focos, de modo a dar conta de todos, às vezes quase simultaneamente (com base em RONCAGLIA, 2010; DANESI, 2013).

Comportamentos tais seguramente são obstáculos para a educação à ausculta, para o "dar ao outro tempo para que se enuncie" (PONZIO, 2013; PONZIO; CALEFATO; PETRILLI, 2007), ou, nos termos de Larrosa (2002), dar-se tempo para pensar mais demoradamente sobre. Para alguns estudiosos, seguramente, essa possibilidade de os sujeitos operarem ao mesmo tempo com um vasto conjunto de estímulos faculta-lhes desenvolvimento psíquico de outra ordem. Essa, no entanto, não é a questão que se coloca para o enfoque deste artigo: o que nos parece significativo é que essa mesma concorrência pela atenção seletiva abrevia o tempo para a ausculta ao outro, apressa o olhar, tangencia o "mergulho" no texto e, como decorrência, tende a superficializar a autoria porque aplana a apropriação de conhecimento, paramétrica para o exercício da criticidade.

A Figura 2 a seguir, no enfoque do recurso ao $a p u d$, exemplifica esse percurso - nela omitimos referenciação de autores em nome de manter a não identificação do texto. Os comentários apontam para a necessidade de rever a fonte de segunda mão, de "desapressar" o olhar, de buscar a origem da enunciação. No conteúdo materializado na Figura todas referências em que constam os apud foram objeto de comentário docente, so- bretudo porque correspondiam a uma mesma obra de um mesmo autor, em um prenúncio de olhar monolítico para o fenômeno em estudo. Segue a Figura:

Figura 2 - Excerto de texto em gênero do discurso da esfera acadêmica

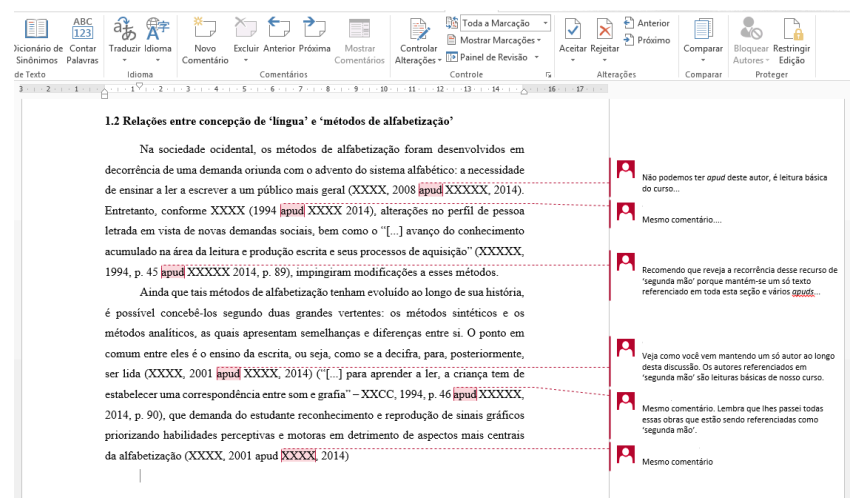

Fonte: GCEE - Acadêmico em final de Curso de Letras, dados gerados em 2015

Ainda em relação à aceleração da atenção seletiva, concebida como obstáculo para a educação à ausculta, condição, por sua vez, para a educação à autoria, referenciamos estudo de Lesnhak (2014), em Núcleo de Práticas Jurídicas de um Curso de Direito, em que a autora discute a larga recorrência da Legislação e da Jurisprudência em petições produzidas por bacharelandos do Núcleo, apontando a baixa incidência do recurso à doutrina como fonte do Direito para finalidades de arrazoados na proposição dessas mesmas petições. A autora infere que a rarefação da voz dos doutrinadores nos textos dos bacharelandos suscita a compreensão de que "[...] agenciar o conteúdo da doutrina implica um vasto universo de leituras e domínio teórico substantivo [...]" e, quando isso não ocorre, dá-se "[...] a possibilidade de, em seu uso, ocorrer contraposição de vertentes teóricas distintas, choque de perspectivas hermenêuticas que não convergem entre si, o que teria implicações em sua inserção na esfera do Direito". (p. 168) E, na remissão à prevalência de novas tecnologias como obstáculo para inserção da voz dos doutrinadores, escreve: “[...] no que tange ao "recorta-e-cola", estaria facultando novos modos sociais de fazer, mas superficializando-os para atender - ou gerar - a pressa da contemporaneidade: não há mais tempo (ou demandas) para encontrar o legislador, o doutrinador e o jurista no âmbito da integrali- 
dade do texto por eles produzido. (p. 171). Finalmente, fecha: "[...] participamos de raras ocasiões em que os textos legais e da doutrina eram consultados na origem, tomados em sua inteireza como tal e, por implicação, na sua complexidade contextual, teórica e epistemológica." (p. 170) Assim, a cultura do "recorta-e-cola" e do apud parece-nos emblemática de tempos de aceleração da atenção seletiva, de abreviação do tempo despendido para o/com o outro, o que impede a criação das condições interlocutivas para a ausculta, ingrediente do encontro (PONZIO, 2013; 2014), condição para o estado de intersubjetividade (WETTSCH, 1985; CERUTTI-RIZZATTI, DELLAGNELO, 2015) e, a partir dele - como propomos na Figura 1, - condição para a autonomia.

Concebemos os dados que compuseram esta seção como indícios de um todo substancialmente maior, uma ponta de iceberg, tomando para outros fins a metáfora de Hamilton (2000). Coloca-se, aqui, uma complexidade significativa para o estudo da educação para a autoria, o que transcende grandemente enfoques de base eminentemente discursiva, ${ }^{15}$ os quais têm caracterizado a literatura da área nos últimos anos. Entendemos que a formação para a autoria implica imersão no simpósio de vozes (BAKHTIN, 2003 [1979]), o que acontece na cadeia discursiva (VOLÓSHINOV, 2009 [1929]), mas não é isomórfico a ela: implica representações do sujeito para a realidade natural e social, as quais se delineiam nas vivências com o outro, no movimento de apropriação do conhecimento - e das valorações a ele correlatas - da heteronomia, do que é interpsíquico, para a autonomia, o que é intrapsíquico. Gaseificações no processo de apropriação do conhecimento, aplanamentos nas perspectivas da esfera acadêmica em relação às demandas de autoria e referendum da velocidade contemporânea dos muitos estímulos para a atenção seletiva, parecem ser componentes relevantes na discussão desse tema e que não podem ser apagados pela exacerbação de olhares focados nos "jogos de linguagem".

\section{Considerações Finais}

Educar para a autoria é função da Educação Básica e da Educação Superior, em um movimento que pre- cisa atender à gradação da escolaridade. Espera-se que a assunção da autoria seja progressivamente mais consolidada à medida que o percurso formativo avança, e isso, em nossa compreensão, tem a apropriação do conhecimento na intersubjetividade, o tensionamento entre o familiar e o novo - sem condescendências de nenhum tipo -, e a formação para a atenção seletiva como questões capitais. Nessa discussão, parece-nos que muitos "paladinos do combate à exclusão", na defesa de posturas relativistas, não raro contribuem largamente para que os estratos populacionais mais fragilizados continuem a sê-lo, sendo "tolerados", ganhando a "condescendência" daqueles estratos que continuam a se apropriar do que é do âmbito do ontogenético. Fica o risco do tom passional em nome de uma defesa que entendemos urgente: os sujeitos precisam apropriar-se de conhecimentos que ampliem o seu repertório cultural para que possam se assumir como autores, em relações intersubjetivas fundadas na criticidade e na assinatura do ato.

\section{Notas}

1. A exemplo da Universidade Aberta do Brasil mantida pelo Ministério da Educação: "O programa busca ampliar e interiorizar a oferta de cursos e programas de educação superior, por meio da educação a distância. A prioridade é oferecer formação inicial a professores em efetivo exercício na educação básica pública, porém ainda sem graduação, além de formação continuada àqueles já graduados. Também pretende ofertar cursos a dirigentes, gestores e outros profissionais da educação básica da rede pública. Outro objetivo do programa é reduzir as desigualdades na oferta de ensino superior e desenvolver um amplo sistema nacional de educação superior a distância (http://portal.mec.gov.br/uab, acesso em dezembro de 2015.)

2. A exemplo da Lei das Cotas n. 12.711/2012, que “(...) garante a reserva de $50 \%$ das matrículas por curso e turno nas 59 universidades federais e 38 institutos federais de educação, ciência e tecnologia a alunos oriundos integralmente do ensino médio público, em cursos regulares ou da educação e jovens e adultos." http://portal.mec.gov.br/cotas, acesso em dezembro de 2015.

3. A exemplo da Emenda Constitucional n. 59, que torna obrigatório o ensino dos quatro aos dezessete anos. http://www.planalto.gov.br/ccivil_03/constituicao/ emendas/emc/emc59.htm, acesso em dezembro de 2015). 
4. Concebemos produtivismo, aqui, com base em Saviani (2013).

5. Entendemos "plena escolaridade", aqui, como alfabetismo pleno tal qual prevê o Indicador Nacional de Alfabetismo Funcional - Inaf (com base no IPM, 2011).

6. A grafia dos sobrenomes em russo atende ao modo como constam nas traduções referenciadas, daí sua variabilidade.

7. A exemplo de Lesnhak (2014) e Mossmann (2014; 2016).

8. Preferimos, aqui, ausculta ao invés de escuta, alinhando-nos ao filósofo italiano aqui referenciado, o qual compreende a ausculta como o abrir-se para o outro, dar tempo a que ele se enuncie, sem apressá-lo. Auscultar implica escutar, mas vai além, aproximandose do calar (reação resposta concebida como não romper o silêncio porque o que é objeto de ausculta "cala fundo") e distinguindo-se do silenciar (postura concebida como decorrente da indiferença: não vale romper com o silêncio, porque o objeto de escuta não toca o sujeito) (PONZIO, CALEFATO, PETRILLI, 2007).

9. A exemplo de abordagens vinculadas, por exemplo, às teorias pós-críticas.

10. Com base em Duarte (2001) e Saviani (2008 [1983]).

11. Alinhamo-nos a Amorim (2009) quando a autora dissocia o olhar bakhtiniano a vertentes pós-modernas, por isso mantemos o autor como parte desta discussão.

12. Autor em cuja obra original Britto (2015) nos convidou a imergir.

13. Em Cerutti-Rizzatti e Dellagnelo (2016), propomos uma articulação entre os conceitos de encontro (com base em PONZIO, 2013; 2014) e intersubjetividade (com base em WERTSCH, 1985), compreendendo que essa articulação comporia o lócus para a apropriação do conhecimento.

14. Nas transcrições dos excertos de entrevistas usaremos as seguintes convenções com base na Análise de Conversa: / - truncamento ou interrupção de fala;

... - pausa de pequena extensão

$(+)$ - pausa breve

$(+++)$ pausa longa

(...) suspensão de trecho da transcrição original

::: - alongamento da vogal

"aaa" - discurso reportado

MAIÚSCULA - trecho com ênfase

[...] inserções nossas para complementação sintáticosemântica

[ ] interrupção de um interlocutor ou falas simultâneas

15. Por 'enfoque de base discursiva', entendemos, aqui, a oposição/denegação de abordagens epistemológicas e ontológicas.

\section{Referências}

AMORIM, Marilia. Para uma filosofia do ato: "válido e inserido no contexto". In: BRAIT, Beth. (org.). Bakhtin: dialogismo e polifonia. São Paulo: Contexto, 2009, p.17-44.

BAKHTIN, Mikhail M. Para uma filosofia do ato responsável. São Carlos: Pedro e João Editores, 2010 [1920-24].

[VOLOCHÍNOV]. O Freudismo: um esboço crítico. 2. ed. São Paulo: Perspectiva, 2010 [1927].

. Os gêneros do discurso. In: Estética da criação verbal. São Paulo: Editora Martins Fontes, 2003 [1952-53], p. 261-306.

Estética da criação verbal. São Paulo: Martins Fontes, 2003 [1979].

BRITTO, Luiz Percival. Ao revés do reverso. São Paulo: Pulo do Gato, 2015.

CERUTTI-RIZZATTI, Mary Elizabeth; MOSSMANN, Suziane da Silva; IRIGOITE, Josa Coelho da Silva. Estudos em cultura escrita e escolarização: uma proposição de simpósio entre ideários teóricos de base histórico-cultural na busca de caminhos metodológicos para pesquisas em Linguística Aplicada. In: Fórum Linguístico, v. 10, n. 1, 2013, p. 48-58.

CERUTTI-RIZZATTI, Mary Elizabeth; LESNHAK, Simone. Apropriação dos modos de dizer na esfera acadêmica: desafios do encontro da outra palavra com a palavra outra. Revista do GELNE (UFC), v. 16, p. 20-35, 2015.

; DELLAGNELO, Adriana Kuerten. Implicações e problematizações do conceito de intersubjetividade: um enfoque na formação do profissional de línguas. Revista Brasileira de Linguística Aplicada (no prelo), 2016.

; GOULART, Anderson. $\mathrm{O}$ ato de dizer nos gêneros do discurso em eventos de letramento: desdobramentos de um simpósio entre conceitos de base teórica distinta. (no prelo), 2016.

DANESI, Marcel. La comunicazione al tempo di Internet. Bari: Progedit, 2013.

DUARTE, Newton. Vigotski e o "aprender a aprender": crítica a apropriações neoliberais e pós-modernas da teoria vigotskiana. 2. ed. rev. e ampl. Campinas, SP: Autores Associados, 2001.

FARACO, Carlos Alberto. Norma culta brasileira: desatando alguns nós. 1. ed. São Paulo: Parábola Editorial, 2008.

FREIRE, Paulo. Pedagogia da esperança. São Paulo: Paz e Terra, 2014 [1992]. 
GERALDI, João Wanderley. A aula como acontecimento. São Carlos/SP: Pedro \& João Editores, 2010.

HAMILTON, Mary. Expanding the new literacy studies: using photographs to explore literacy as social practice. In: ; BARTON, David; IVANIC, Roz (org.). Situated literacies. London: Routledge, 2000. p. 12-29.

HELLER, Agnes. O cotidiano e a história. Trad. Carlos Nelson Coutinho e Leandro Konder. 10. ed. São Paulo: Paz e Terra, 2014 [1970].

IPM - Instituto Paulo Montenegro \& Ação Educativa. INAF BRASIL 2011: principais resultados. São Paulo: IPM / Ação Educativa, 2011.

LARROSA, Bondía Jorge. Notas sobre a experiência e o saber de experiência. Revista Brasileira de Educação. n. 19, jan/fev/mar, 2002. p.20-28

LESNHAK, Simone. O sujeito na relação com o outro por meio da escrita: a apropriação de modos de dizer para inserção profissional na esfera jurídica. Tese (Doutorado em Lingüística) - Universidade Federal de Santa Catarina, 2014.

LEA, Mary R.; STREET, Brian V. Student writing in higher education: an academic literacies approach. Studies in Higher Education. V.23, p. 157, 16p, 1998.

LILLIS, Theresa M. Student writing: access, regulation, desire. Londres: Routledge, 2001.

LYOTARD, Jean-François. A condição pós-moderna. 15. ed. Rio de Janeiro: José Olympio, 2013 [1979].

MINAYO, Maria Cecília de Souza. (Org.). Pesquisa social: teoria, método e criatividade.Petrópolis, 14 ed. RJ: Vozes, 2014 [1993].

MOSSMANN, Suziane da Silva. O ato de dizer entre Babel e Pentecostes: um estudo sobre os usos sociais da escrita na esfera acadêmica. Dissertação (Mestrado em Linguística) - Universidade Federal de Santa Catarina, Florianópolis, 2014.

Círculo de estudos de formação para a docência. Projeto de tese de doutorado. (Doutorado em Linguística) - Universidade Federal de Santa Catarina, Florianópolis, 2016.

Identidade e mercado de trabalho: dois dispositivos de uma mesma armadilha mortal. In: MIOTELLO, Vladimir; MOURA, Maria Isabel. A alteridade como lugar da incompletude. São Carlos/ SP: Pedro e João Editores, 2014, p. 49-95.

La Filosofia del Linguaggio. Bari: Laterza, 2011.

Procurando uma palavra outra. São Carlos/SP:

Pedro \& João Editores, 2010.
.; CALEFATO, Patrizia; PETRILli, Susan. Fundamentos de Filosofia da Linguagem. Rio de Janeiro: Vozes, 2007.

RONCAGLIA, Gino. La quarta rivoluzione. Bari: Laterza, 2010.

SAVIANI, Demerval. Escola e democracia: polêmicas do nosso tempo. Campinas, SP: Autores Associados, 2008 [1983].

História das ideias pedagógicas no Brasil. 4. ed. Campinas, SP: Autores Associados, 2013.

VIGOTSKI, Lev Semenovich. A formação social da mente. São Paulo: Martins Fontes, 2000 [1968].

VIGOTSKI, Lev Semenovich. A construção do pensamento e da linguagem. São Paulo: Martins Fontes, 2001 [1934].

VYGOTSKI, Lev. Semenovich. Obras escogidas. Tomo III. Madri: Visor, 2012 [1931].

VOLÓSHINOV, Valentin Nikoláievich. El Marxismo y la filosofía del lenguaje. Buenos Aires: Ediciones Godot, 2009 [1929].

VOLOCHÍNOV, Valentin. Que é linguagem? In:

A construção da enunciação e outros ensaios. São Carlos/SP: Pedro e João Editores, 2013 [1930], p. 131156.

WERTSCH, James. Mind as action. New York: Oxford University Press, 1985.

Recebido em: 27/02/2016 Aceito em: 27/07/2016 